\title{
PROGRAM OF SOCIO-PEDAGOGICAL PREVENTION OF ANXIETY IN ADOLESCENTS IN THE CONDITIONS OF A GENERAL EDUCATIONAL SCHOOL
}

\author{
Akmaral Magauova \\ Al-Farabi Kazakh National University, Kazakhstan \\ Galiyabanu Kertayeva \\ L.N. Gumilyov Eurasian National University, Kazakhstan \\ Zhanel Dukenbayeva \\ Al-Farabi Kazakh National University, Kazakhstan
}

\begin{abstract}
This article discusses the problem of substantiating the need for social and pedagogical prevention of anxiety in adolescents in a general education school and the organization of the educational process, which takes into account the peculiarities of anxiety in adolescents. A theoretical analysis of the literature and the study of the experience of educational work in general education schools allow us to conclude that the educational process is not sufficiently focused on the prevention of anxiety among adolescents among the middle level.

The aim of the research is to develop and approbate a program of social and pedagogical prevention of anxiety in adolescents in a comprehensive school. The structure of the study is based on the requirements of modern higher education, which is based on the professional competencies of the educational paradigm. The main results of the study allow us to determine the effectiveness of the developed program for the prevention of anxiety in adolescents. Based on the results of the analysis of the theory, the structure and methods of a social-pedagogical program for the prevention of anxiety will be revealed, using the example of the use of the methodology "Personal school of anxiety by J. Taylor" (1953). The question of the research is how to develop a program of social and pedagogical prevention of anxiety in adolescents, which will be systemic, holistic, personal and active in nature and will be effective.
\end{abstract}

Keywords: anxiety, adolescent children, school anxiety, the program of social and pedagogical prevention of anxiety.

\section{Introduction}

One of the most crucial stages in every person's life is adolescence. In this difficult period of a child's life, at a qualitatively new level, his development 
Magauova et al., 2021. Program of Socio-Pedagogical Prevention of Anxiety in Adolescents in the Conditions of a General Educational School

potential is realized as an active subject, cognizing the world around him and himself, also acquiring his own experience of activity in this world.

Anxiety as a violation of the emotional sphere of the personality is a stable formation that persists for a long period of time and indicates the child's insufficient adaptability to certain social situations. Anxiety is a serious risk factor for the development of many neurotic and psychosomatic disorders.

Consequently, in the rapidly developing 21st century, one of the most pressing problems in the field of pedagogy, social pedagogy, psychology is the prevention of anxiety in adolescent children.

The relevance of this study is associated with the existing urgent need to create a special preventive educational program for working with adolescent students.

Research methods: theoretical analysis, survey, questioning; long-term observation using specially designed programs; pedagogical experiment.

\section{Main Part}

Different definitions of anxiety can be found in pedagogical and psychological literature, however, most researchers agree on recognition of the need to consider this concept differentially, as a situational phenomenon and as personal characteristics taking into account transient condition and its dynamics.

For instance, A.M. Prikhozhan (2007) specifies that anxiety is experience of emotional discomfort, related to expectation of ill-being with a presentiment of impending danger.

In the most general terms, anxiety is thought of as a negative emotional experience, which is somehow related to the presentiment of danger or anxiety. The fact that anxiety, along with fear and hope, is a special, anticipating emotion, explains its special position among other emotional phenomena.

Anxiety in adolescence is included in the complex of various negative emotional experiences; aggressiveness, hostility, negativism, suspicion, guilt, resentment, frustration are the most common ones among them.

The theoretical basis of the study as follows: the provision on the unity of age patterns of development of a normal and abnormal child by L.S. Vygotskiy et al. (2012), V.I. Lubovskiy \& S.M. Valyavko (2010), T.A. Vlasova \& M.S. Pevzner (1973); studies of L.S. Vygotskiy et al. (2012) on the role of social factors in the prevention and developmental disorders; sociological and psychological-pedagogical theories on the social development of a person, the mechanisms of his socialization (Andreeva, 2009; Mudrik, 1981); the concept of humanization of education; personality-oriented, competence-based and activity-based approaches; the theory of personality attitudes (Bodalev, 1970; Lazurskii, 1997; A. Leontiev \& D. Leontiev, 2005). 
Some Russian scientists such as: L.I. Bozhovich (2006), M.S. Neimark (1959), B.I. Kochubei (1988) should also be noted on research of this subject. Especially, it is necessary to emphasize the contribution of A.M. Prikhozhan (2007) in study of anxiety in children and adolescents.

In Republic of Kazakhstan, such problems and the study of anxiety were considered in the works of such famous scientists as: Zh.I. Namazbaeva (2012), S.M. Dzhakupov (2008), Z.B. Madalieva (2014) and others.

Theoretical analysis of the literature and the study of the experience of educational work in general education schools allow us to conclude that the educational process is not sufficiently focused on the prevention of anxiety among adolescents of the middle level.

There is still contradiction between the necessity for holding sociopedagogical prevention of anxiety in adolescent children and insufficient research of this issue in the field of social pedagogy in real pedagogical process of the school until the current time.

Abovementioned contradiction defined the problem of the study, which consists in substantiating the need for the implementation of socio-pedagogical prevention of anxiety in adolescents in the condition of a general education school and the organization of the educational process, which takes into account the peculiarities of anxiety in adolescents.

Aim of the study is recognized as a development of the program of methods for organizing social and pedagogical prevention of anxiety in adolescents in condition of a general education school.

Object of the study: social and pedagogical process of general education school.

Subject of the study: program of social and pedagogical prevention of anxiety in adolescents.

Research objectives:

1. Analyze the theoretical bases of the social and pedagogical prevention of anxiety in adolescents in conditions of a general education school.

2. To reveal the essence of the concept of the adolescent anxiety in the context of modern social and pedagogical realities.

3. To develop and test a program in experimental and pedagogical work for the social and pedagogical prevention of anxiety in adolescents in condition of a general education school.

The number of children who experiencing anxiety, often associated with school life, academic performance, relationships with parents, peers, and emotional discomfort is currently increased.

The anxiety develops into a chronic, high-flown condition for some adolescents that interferes with their ability to attend school and achieve academic success. Participation in extracurricular activities, meeting new 
Magauova et al., 2021. Program of Socio-Pedagogical Prevention of Anxiety in Adolescents in the Conditions of a General Educational School

people, chatting with friends, maintaining a supportive and flexible family relationships become difficult issue for the child. Sometimes anxiety is limited to generalization, a slight feeling of anxiety or discomfort. In other cases, it can also develop into panic attacks and phobia (Barker, 2003).

At first sight, there are similar concepts such as apprehension and anxiety. Anxiety is experience of emotional discomfort, related to the expectation of illbeing, with presentiment of impending danger. Anxiety is distinguished as an emotional condition and as a stable property, personality trait or temperament (Prikhozhan, 2000).

Currently, various definitions of the determination of the anxiety concept are used in the pedagogical and psychological literature however, at the same time, most researchers are of the same opinion on the need to consider it differentially - as a situational phenomenon and as a personal characteristic, taking into account the transitional condition and its dynamics.

Cases in which people differ to a certain extent from each other in terms of anxiety level happen quite often. In order to measure such individual differences, the American scientist J. Taylor (1953) developed a test that consisted of a number of statements, in particular, such as "I often have nightmares" or "I can easily get confused".

Over the course of time, it became clear to researchers that there are two types of anxiety: the first, as a more or less stable personality trait; and the second, as an individual's reaction to a threatening situation. Despite the fact that these two types of anxiety are completely individual categories, there is a certain connection between them. According to H. Hekhauzen (1964) there are clearer differences between people with high and low levels of anxiety, under the influence of disturbing and threatening phenomena (pain, stress, threat to social status, etc.).

Within the framework of this article and the theoretical analysis of the literature, we have developed the Program for the social and pedagogical prevention of anxiety in adolescents in the condition of a general education school.

Each lesson according to the program of the social and pedagogical prevention of anxiety in adolescents includes exercises to create a positive attitude, active neuromuscular relaxation, mutual understanding, increase selfesteem and self-confidence, team building, and providing feedback and reflection.

In order to determine the effectiveness of the developed program on prevention of anxiety in adolescents, we used the method of the Personal scale of anxiety manifestations (Taylor (1953), adapted by Nemchinova, 2012). Diagnosis results for the method of the Personal scale of anxiety manifestations are presented in the Table 1. 
Table 1 The Anxiety Level of Adolescents at the Ascertaining Stage of the Study (in \%) on the Methodology of the Personal Scale of the Anxiety Manifestations (Tailor (1953), adapted by Nemchinova, 2012)

\begin{tabular}{|l|l|l|l|l|}
\hline \multirow{2}{*}{ The anxiety level } & \multicolumn{3}{|l|}{$\begin{array}{l}\text { Experimental group (20 } \\
\text { students) }\end{array}$} & \multicolumn{2}{l|}{$\begin{array}{l}\text { Control group (23 } \\
\text { students) }\end{array}$} \\
\cline { 2 - 5 } & quantity & $\%$ & quantity & $\%$ \\
\hline Very high & 2 & 10 & 0 & 0 \\
\hline High & 9 & 45 & 6 & 26,08 \\
\hline Medium with a tendency to high & 4 & 20 & 2 & 8,7 \\
\hline Medium with a tendency to low & 2 & 10 & 8 & 34,8 \\
\hline Low & 3 & 15 & 7 & 30,4 \\
\hline
\end{tabular}

$10 \%$ of adolescent children in the experimental group with a very high level of anxiety were detected according to results of the study, which was conducted with the methodology of the Personal scale of manifestations of anxiety (Taylor (1953), adapted by Nemchinova, 2012). High level of anxiety was detected in $45 \%$ of observed ones, they are, 9 adolescents in the experimental group. Also, Medium with a tendency to high level of anxiety in $20 \%$ of observed adolescents in the experimental group was detected by us. These students require increased attention, as these results indicate that these children tend to experience anxiety of various degrees of intensity, in particular at a medium and high level, while at school as in following cases: in the process of learning, testing and evaluation of knowledge in the process of communication and interaction with teachers and peers, etc.

According to our study, systematic observation, and also pedagogical analysis it was detected that students get more interested in learning activities such as: doing homework, getting less distracted by side matters in the classroom; answering the question of teacher without worry and anxiety.

During the participation of children in the program, aimed at social and educational prevention of anxiety in adolescents in the condition of general education school, they became more confident, more dynamic, academic performance has improved significantly, and also teachers of the class noticed some positive changes, having shown interest in the conducted prevention program.

As a result of considering this issue, it can be argued that the program of the social and educational prevention of anxiety in the condition of general education school is effective in the case of improving the performance level of anxiety in children after repeated diagnosis of anxiety level of children with applying the diagnostic methodology of the Personal scale of the anxiety manifestations (Taylor (1953), adapted by Nemchinova, 2012). 
Magauova et al., 2021. Program of Socio-Pedagogical Prevention of Anxiety in Adolescents in the Conditions of a General Educational School

Table 2 Thematic Plan of the Program of Classes on Social and Pedagogical Prevention of Anxiety in Adolescents in the Conditions of a General Education School

\begin{tabular}{|c|c|c|c|}
\hline № & Study subject & Aim of the study & $\begin{array}{l}\text { Q-ty of } \\
\text { hours }\end{array}$ \\
\hline \multicolumn{4}{|c|}{ INTRODUCTORY STAGE } \\
\hline 1 & Introductory lesson & $\begin{array}{l}\text { creating a positive mood, emotional and muscle } \\
\text { relaxation of students, acquaintance of students. }\end{array}$ & 2 \\
\hline \multicolumn{4}{|c|}{ MAIN STAGE } \\
\hline 2 & $\begin{array}{l}\text { What is anxiety? How } \\
\text { to cope with it? }\end{array}$ & $\begin{array}{l}\text { Definition of the concept of anxiety, fear, worry, the } \\
\text { study of ways to overcome anxiety. }\end{array}$ & 2 \\
\hline 3 & $\begin{array}{l}\text { Anxiety and Self- } \\
\text { Esteem }\end{array}$ & $\begin{array}{l}\text { Definition of the concept of the Anxiety and Self- } \\
\text { Esteem, the importance of self-confidence }\end{array}$ & 2 \\
\hline 4 & I dream of ... & $\begin{array}{l}\text { Creation of a collaborative environment, positive } \\
\text { attitude with the aim of active participation of children } \\
\text { in the lesson }\end{array}$ & 2 \\
\hline 5 & $\begin{array}{l}\text { I appreciate / } \\
\text { I am grateful for... }\end{array}$ & $\begin{array}{l}\text { Creation of a positive emotional attitude, } \\
\text { determination of the concept of gratitude. }\end{array}$ & 2 \\
\hline 6 & $\begin{array}{l}\text { Music as the harmony of } \\
\text { the soul }\end{array}$ & $\begin{array}{l}\text { Creation of a positive attitude, conducting the } \\
\text { meditation, determination of influence of the music on } \\
\text { emotional condition of the human's soul. }\end{array}$ & 2 \\
\hline 7 & $\begin{array}{l}\text { United we are the } \\
\text { power! }\end{array}$ & $\begin{array}{l}\text { Determination of the importance of friendship in a } \\
\text { person's life and the potential of friendship in certain } \\
\text { situations. }\end{array}$ & 2 \\
\hline 8 & $\begin{array}{l}\text { "Audio story as a way of } \\
\text { expressing the inner } \\
\text { experiences of children" }\end{array}$ & $\begin{array}{l}\text { The development of the verbal personality traits of a } \\
\text { adolescent with the help of recording of audio stories. }\end{array}$ & 2 \\
\hline 9 & Puppet show & $\begin{array}{l}\text { Creation of a positive attitude, developing the inner } \\
\text { creative potential of children. }\end{array}$ & 2 \\
\hline 10 & $\begin{array}{l}\text { Fairy tale with deep } \\
\text { meaning }\end{array}$ & $\begin{array}{l}\text { Formation of moral qualities of adolescents, using } \\
\text { fairy tales as the method of manifestations of the basic } \\
\text { thoughts of the child. }\end{array}$ & 2 \\
\hline 11 & $\begin{array}{l}\text { Meditation is the path to } \\
\text { tranquility }\end{array}$ & $\begin{array}{l}\text { Concentration on breathing, positive attitude, } \\
\text { definition of meditation. }\end{array}$ & 2 \\
\hline \multicolumn{4}{|c|}{ THE FINAL STAGE } \\
\hline 12 & $\begin{array}{l}\text { Everything depends on } \\
\text { ourselves }\end{array}$ & $\begin{array}{l}\text { Creation of a collaborative environment, the concept } \\
\text { of life values, their role in the formation of a person's } \\
\text { qualities. }\end{array}$ & 2 \\
\hline
\end{tabular}

Methodology of the Personal scale of manifestations of anxiety (Taylor (1953), adapted by Nemchinova, 2012) was conducted repeatedly after the implementation of the complex of lessons of the program, aimed at the social and pedagogical prevention of anxiety in adolescents in the condition of a general education school. 
Proceedings of the International Scientific Conference. Volume III, May $28^{\text {th }}-29^{\text {th }}$, 2021. 327-336

Table 3 The Level of Anxiety in Adolescents at the Control Stage of the Study according to the Methodology of the Personal Scale of Manifestations of Anxiety (in percentage scale)

\begin{tabular}{|c|c|c|c|c|}
\hline \multirow[t]{2}{*}{ The level of anxiety } & \multicolumn{2}{|c|}{$\begin{array}{lll}\begin{array}{l}\text { Testing } \\
\text { students })\end{array} & \text { group } & \text { (20 }\end{array}$} & \multicolumn{2}{|c|}{$\begin{array}{l}\text { Control group } \\
\text { (23 students) }\end{array}$} \\
\hline & Quantity & $\%$ & Quantity & $\%$ \\
\hline Very high & 0 & 0 & 0 & 0 \\
\hline High & 2 & 10 & 5 & 21,73 \\
\hline Medium with a tendency to high & 4 & 20 & 3 & 13,04 \\
\hline Medium with a tendency to low & 9 & 45 & 9 & 39,13 \\
\hline Low & 5 & 25 & 6 & 26,08 \\
\hline
\end{tabular}

Comparative analysis of the data in Tables 1 and 3 indicates that the level of anxiety in comparison with the ascertaining stage of the study is significantly decreased in students of the test group after conducted complex of the classes of the program of social and pedagogical prevention of anxiety in adolescents in a general education school.

The bar graph (Figure 1) was designed in order to visualize the comparative analysis of the results of experimental work of the ascertaining and control stages of the study based on the data of Tables 1 and 3.

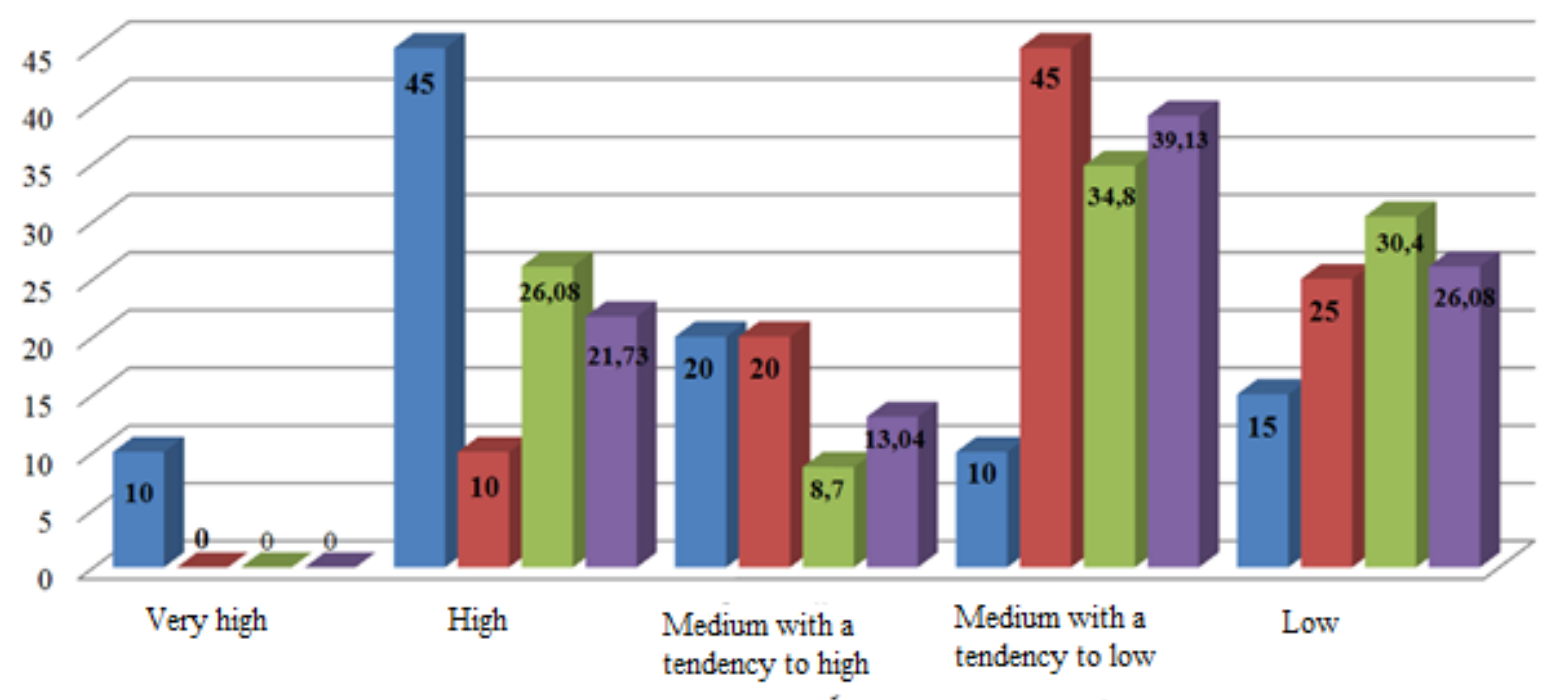

-IASCERTAINING STAGE (TEST GROUP)। Control stage (Test group)

-ASCERTAINING STAGE (CONTROL GROUP) "Control stage (Control group)

Figure 1 The Bar Graph of Comparing the Diagnostic Results of the Personal Scale of Manifestations of Anxiety (J. Tailor) of Students of the Test and Control Groups on the Ascertaining and Control Stages of the Study (in percentage scale) 
Magauova et al., 2021. Program of Socio-Pedagogical Prevention of Anxiety in Adolescents in the Conditions of a General Educational School

Due to the conducted program of the anxiety prevention, during the analysis of results of the control stage of the study, we detected that majority of students of the class have low and optimal indicators of level of the school anxiety.

\section{Conclusion}

Adolescence is a difficult period of puberty and psychological maturation for every child. Significant changes happen in the consciousness of adolescent, such as facing the feelings of maturity, feeling oneself adult, there comes a passionate desire to at least seem like an adult and be considered as an adult.

Friendly relations, interaction of students with each other and association in informal groups are formed in this certain stage of person's life. Also, the pursuit to be like their peers in everything, try to stand out in the group and be the best, earn the respect and disposition of others, overcome existing shortcomings, demand loyalty, faith, etc. is noted. Having completed our conducted test work, we can make a conclusion, that all received data during the test work indicate that activity on the implementation of social and pedagogical prevention of anxiety in adolescents in the condition of a general education school was productive and effective.

That means, results and comparative analysis of the study specifies a need for work, aimed at preventing anxiety and worry in adolescents.

Therefore, the final data that we obtained during the control stage of the research work shows the effectiveness of the developed program of social and pedagogical prevention of anxiety in adolescents in the conditions of a general education school.

Results of the conducted study according to the social and pedagogical prevention and reduce of school anxiety among adolescents in condition of the general education school offer the following recommendations:

- create proper conditions to develop general and individual skills, creative potential of students to prevent anxiety, increase self-esteem, self-confidence (with the help of music therapy, drawing, vocals, poetry, sports etc.).

- selection of educational and methodological material during the preparation for the classes should be carried out properly, do not overload students with information;

- $\quad$ evaluation of the students should be reasoned, it is necessary to use reasoning as means to achieve the learning goals and objectives, and also create adequate attitude to notes and grades; 
- create a favorable psychological and pedagogical climate in the classroom and provide emotional support to students;

- $\quad$ in order to prevent adolescent anxiety, it is important to familiarize them with the methods of self-organization of educational and leisure activities, teach planning and distribution of own spare time; develop the self-regulation, skills and abilities that increase self-confidence;

- parents should be informed about a high level of worry and anxiety of the child, about his behavior, academic performance, communication with classmates, and ways to reduce anxiety.

- $\quad$ carry out the conduction of diagnostics, researches, aimed at studying the level of anxiety of schoolchildren;

- $\quad$ organization of preventive activities aimed at preventing and reducing the general level of anxiety among students;

- providing necessary assistance, consultations to adolescents with anxiety, informing parents and teachers about received results;

- teaching the methods of self-regulation, stress-resistance, formation of positive thinking and positive self-concept, reasonable self-esteem to the children;

- developing the communication skills of social interaction with surroundings in adolescents, self-reflection skills, formation of the ability to analyze the events, receiving a positive experience, making perspective plans;

- organizing the training classes with teachers and parents, aimed at studying the concept of anxiety, the factors of anxiety and ways to overcome it.

\section{References}

Andreeva, G.M. (2009). Social psychology today: searches and reflections. Moskva: Nauka.

Barker, P (2003). Psychiatric and Mental Health Nursing: The Craft of Caring. London: Edward Arnold.

Bodalev, A.A. (1970). Formirovanie ponjatija o drugom čeloveke kak ličnosti. Leningrad: Izdat. Leningradskogo Univ.

Bozhovich, L.I. (2006). Speech and practical intellectual activity of a child (experimental theoretical research). Cultural-Historical Psychology, N 1-3.

Dzhakupov, S.M. (2008). Psychological structure of the learning process, 2nd ed. Almaty: Kazak, University, 308 p.

Kochubei, B.I., (1988). Emotional stability of a schoolchild. Moscow: Knowledge.

Lazurskii, A. F. (1997). Izbrannye trudy po psikhologii. Moskva: Nauka.

Leontiev, A.A., Leontyev, D.A., (2005). A.N. Leontiev: activity, consciousness, personality. M.: Moscow.

Lubovskiy, V. I., Valyavko, S. M. (2010). Terminological problems of special psychology and special pedagogy. Cultural-historical psychology, 2010, no. 1, 50-55. 
Magauova et al., 2021. Program of Socio-Pedagogical Prevention of Anxiety in Adolescents in the Conditions of a General Educational School

Madalieva, Z.B. (2014). Features of the development of subjective properties in adolescence. KazҰU KHABARSHYSY, 78 p.

Mudrik A.V. (1981). Communication as a factor in the upbringing of schoolchildren. Abstract dis. for the degree of Doctor of Pedagogical Sciences: 13.00.01 - Theory and history of pedagogy. L.: Leningrad Order of the Red Banner of Labor State Pedagogical Institute named after A. I. Herzen.

Namazbaeva, Zh.I. (2012). Psychological foundations of the development of a creative intellectual personality in an educational environment: monograph. Almaty.

Neimark, M.S., (1959). Some psychological conditions for the effectiveness of educational influence, communication 2. Reports of the APN RSFSR, No. 5.

Prikhozhan, A.M. (2000). Anxiety in children and adolescents: psychological nature and age dynamics. M.: Moscow, Psychological and Social Institute; Voronezh: Publishing house NPO "MODEK".

Prikhozhan, A.M. (2007). Psikhologîia trevozhnosti: Doshkol'nyı̆ i shkol'ny̌̌ vozrast. SanktPeterburg: Piter.

Taylor, J. (1953). Personal scale of anxiety. Adaptation of T.A. Nemchinova. Diagnostics of emotional and moral development. St. Petersburg, 2012. 126-128.

Vlasova, T.A., Pevzner, M.S. (1973). On children with developmental disabilities. M.: Moscow "Education".

Vygotskiy, L.S., Vygotsky, L.S., \& Robbins, D. (2012). The collected works of L.S. Vygotsky. New York, NY: Springer-Verlag New York. 